\title{
Psychosocial-Stress, Liver Regeneration and Weight Gain: a Conspicuous Pathophysiological Triad
}

\author{
Syeda Momna Ishtiaq ${ }^{\mathrm{a}} \quad$ Junaid Ali Khan ${ }^{\mathrm{a}} \quad$ Muhammad Imran Arshad $^{\mathrm{b}}$ \\ aInstitute of Pharmacy, Physiology and Pharmacology, University of Agriculture, Faisalabad, 'Institute of \\ Microbiology, University of Agriculture, Faisalabad, Pakistan
}

\section{Key Words}

Stress $•$ Glucocorticoids $•$ Liver pathophysiology $・$ Regeneration $\bullet$ Weight gain $•$ Obesity

\begin{abstract}
Psychosocial stress alters several physiological parameters resulting in multiple disorders, particularly compromising the immune system thereby provoking various diseases including liver disorders. However, the plausible underlying mechanisms remain elusive. Recent literature provides mechanistic evidences of detrimental effects of psychosocial stress on physiology of different body organs including liver. The data of stress-induced pathophysiological changes in liver functions and obesity were systematically collected from PubMed, ScienceDirect and the Web of Science Databases published in English. Stress and glucocorticoids (GCs) control food intake and energy expenditure through appetite stimulators neuropeptide $Y$ (NYP) and agouti-related protein (AgRP) in hypothalamus. Principle effectors of the activated hypothalamic-pituitary-adrenal (HPA) axis in response to psychosocial stress are proopiomelanocortin (POMC)-derived adrenocorticotropic hormone (ACTH) and GCs. Stressinduced GCs hyper-secretion triggers glucocorticoid receptor (GR)-dependent transcriptional factor, nuclear factor kappa B (NFKB), which interferes TNF $\alpha$-IL6 and keap1-Nrf2 pathways in liver regeneration and obesity through fine-tuning of TNF $\alpha$, IL6 and Nrf2 signaling. In this review, it is contrived upon existing evidence to put forward a model whereby exposure to life-stress has a prominent impact over weight gain and can alter the regenerative mode of a damaged liver through Keap1-Nrf2 and TNFa-IL6 pathways.

\section{Introduction}

Liver is a vital organ with a central role in maintaining metabolic homeostasis [1]. Despite of being a detoxifying organ, the liver has a great capability to regenerate [2]. The liver is comprised of liver parenchymal cells and liver non-parenchymal cells. Liver nonparenchymal cells consist of hepatic oval cells, Kupffer cells, and other cell types. Hepatic oval cells in rodents and adult hepatic stem/progenitor cells, termed as hepatic progenitor cells (HPCs) in humans [3], are a kind of stem cells with the potential to differentiate into

Junaid Ali Khan, Assistant Professor

KARGER 
liver cells including hepatocytes that help in liver regeneration process [4]. Normally, most of adult liver oval cells is in the quiescent state. After an injury or partial hepatectomy they can rapidly enter the cell cycle and play a complementary role in the hepatocytes proliferation $[5,6]$.

Accumulating evidence indicate an association between psychosocial stress and liver diseases [7, 8], markers of inflammation as well as liver disease risks [9]. In recent years, the role of stress mediators in the liver pathophysiology has gained a new dimension [8, $10,11]$. Deviant increase in glucocorticoids following stress-arousal influences both food consumption and energy expenditure $[12,13]$. Studies in human subjects strongly suggest a correlation between prolonged elevation of circulating glucocorticoids and weight gain [14]. It has been acknowledged for years that, subsequent to chemical or surgical insult, the liver undergoes repairs processes to regenerate tissue possessing anatomical or functional characteristics of hepatocytes [15]. During this phenomenon, several types of liver cells comprising hepatocytes, fibroblasts, dendritic cells (DCs), liver sinusoidal epithelial cells (LSECs), vascular endothelial cells (VEC) $[5,16]$ and signaling molecules including cytokines; interleukin 6 (IL6), tumor necrosis factor alpha (TNF $\alpha$ ) and growth factors; transforming growth factor alpha (TGF $\alpha$ ), transforming growth factor beta (TGF $\beta$ ), hepatocyte growth factor alpha $(\mathrm{HGF} \alpha)$ contribute to regenerate the damaged liver [2] followed by controlled inhibition through feedback mechanisms [17]. Hepatic stimulatory substance, hepatopoietin, also known as augmenter of liver regeneration (ALR), is a protein specifically produced and secreted from hepatocytes [18]. The ALR has immunoregulatory and cytoprotective effects of liver injury [19]. The ALR stimulates synthesis of TNF $\alpha$, IL6 and nitric oxide in Kupffer cells $[18,20]$ which play important roles in repairing processes. Previous studies regarding hepatic recovery following partial hepatectomy and liver injuries strongly describe the involvement of various active growth factors such as $\operatorname{HGF}[21,22]$, TGF- $\alpha$ [16], tumor necrosis factor alpha $(\mathrm{TNF} \alpha)$ and epidermal growth factor (EGF). It has been reported that the cytokines TNF $\alpha$, IL6 [21], transcription factor NFKB [23] and immediate early response genes [6] are involved in liver regeneration process. Also during early stage of liver regeneration [2, 21], increased cortisol secretion in response to stressful conditions mobilizes the metabolic energy to prepare the body for emergency situations. Persistent stress is also accompanied by an increase in cytokines [10,11], oxidative stress, reactive oxygen species (ROS) [24] and increased reactive nitrogen species (RNS) production [25] which are known to interfere the regulatory mechanisms of liver regeneration.

This article reviews the current literature related to psychosocial stress and its effects on liver regeneration and body weight. It is hypothesized that cellular responses initiated because of chronic stressful events may interfere hepatic regeneration mechanisms by disrupting normal physiology either promoting or inhibiting feedback mechanisms following partial hepatectomy and liver injuries. Therefore, the goal of this review is to discuss psychological stimuli, which trigger excessive body weight gain and interfere liver regeneration processes.

\section{The impact of psychosocial stress and glucocorticoids on body weight and liver physiology}

Stress related factors in response to psychosocial distress have been the focus of study for contemporary sciences $[11,26]$. Various stressful life events are reflected as "stressor" [11] which adversely affect the physiological processes. High intensity and/or long term exposure to circulating GCs are capable of showing the profound effects on intake of "comfort food" (fat and sugar, enriched food) that in turn cause a relative increase in body weight and subsequent obesity [14]. Once exposure to stressor, specific pathways within the brain lead to activation of the hypothalamo-pituitary-adrenal (HPA) axis as well as central sympathetic outflow. This constitutes the stress response with the release of key peripheral mediators 
"glucocorticoids and catecholamines" [25]. In response to activation of the HPA axis, POMCderived ACTH stimulates adrenal cortex to release GCs. Moreover, POMC influences synaptic inputs for appetite stimulators NPY and AgRP. It stimulates the nexus in the hypothalamus that controls food intake which may lead to weight gain [14]. The normal physiology of food intake and energy expenditure is managed by functioning of POMC cells as well as the number of excitatory inputs to neuroendocrine systems $[27,28]$. There is a strong nexus among endocrine system and the stress response controlled by the nervous system. The arcuate nucleus of the hypothalamus contains distinct populations of neurons, which contain appetite stimulators NPY and AgRP. This linkage of systems is highly influenced by long-term stress resulting in altered physiological parameters and causes excessive weight gain leading to obesity [29-35].

The GCs play important role in restoration of homeostasis in response to psychological stress by mediating their effects via GR [36]. The GR, a nuclear receptor, is abundantly expressed in hepatocytes and other liver cells [37] and plays diverse roles in many cellular functions including cell proliferation [38]. The GCs act either via modulation of GR-independent cell membrane components (involving GCs-physiochemical interactions with components of cell membrane), cell membrane-bound GR (involving a MAPK pathway) or cytoplasmic GR to initiate rapid non-genomic cell signaling events [39-41]. The functioning of cytoplasmic GR involves a conformational change upon ligand binding, dissociation of heat shock proteins (chaperones) complex and nuclear localization of the ligand-bound receptor. The ligandGR complex invokes transcriptional effects, either positive or negative through interactions with distinct liver specific transcriptional co-regulators and transcription factors [42] such as CCAAT/enhancer binding protein (c/EBP) [43], hepatic nuclear factor (Hnf4) [44, 45], Forkhead factor A2 (FoxA2) [46] and Forkhead factor 01 (Fox01) [47]. Anti-inflammatory activity of GR is mediated at least partially by interactions with transcriptional co-repressors inhibiting the expression of several inflammatory mediator genes. The transcription of $\mathrm{NF} \kappa \mathrm{B}$, one of the nuclear factors which control the expression of inflammatory cytokines, is repressed by GCs action [48, 49]. Interestingly, in a recent report, GR-prompted leucine zipper (GILZ) pathway in Kupffer cells is shown to be associated with obesity due to down regulation of GR [50] and it promotes the liver proliferation by activation of NFKB [51]. At the cellular level, GCs target several cellular functions to affect liver regeneration. Noticeable rise in ROS production, because of excessive glucocorticoids secretion during prolonged stress, activates liver degenerative processes through extrinsic and intrinsic pathways of cell death. Alongside these detrimental effects of the glucocorticoids, "The Kelch ECH associated protein 1 (Keap1) -Nrf2 pathway" which promotes liver regeneration [14, 52] is also activated by the glucocorticoids. Thus, both apoptosis and regenerative pathways are fine-tuned by the glucocorticoids signaling and the outcome would be determined by alteration in any of the two mechanisms.

\section{Pathways linking psychosocial stress to liver regeneration}

Psychological stressors are often linked to social environment, natural or man-made disasters, socioeconomic conditions and lifestyle. The stresses or even the memory of the stressful events impacts the individuals over an extended period, thereby constituting chronic psychosocial stress [53]. The HPA axis and adrenomedullary system are key components of the stress system. Their main function is to maintain the basal and stressrelated homeostasis. All key hormones secreted by HPA components play different roles in modulation of immune response. Hepatic cellular functions are influenced by GCs, as they suppress cytokine immune activation by inhibiting the production of other cytokines and inflammatory mediators $[11,26]$ (Fig. 1).

Liver regeneration is a compensatory mechanism of hepatic mass proliferation in response to tissue resection or injuries caused by toxins, drugs or viral infections $[54,55]$. 
Detailed studies of the mechanisms that regulate liver growth have been done in animals subjected to partial hepatectomy or chemical injury [6]. Hepatocytes priming by the cytokines TNF $\alpha$ and IL6 along with other agents is required for the optimal regenerative potential in response to growth factors; HGF, TGF $\alpha$, and EGF [56]. The proliferative or apoptotic effect of TNF is influenced and determined by the ROS and glutathione contents in hepatocytes. In addition to growth factors, at least four transcription factors, NFkB, STAT3 (which are strongly induced by TNF $\alpha$ ), AP-1 and $\mathrm{C} / \mathrm{EBP} \beta$ play important roles in the initiation of liver regeneration [57]. In addition, extensive remodeling of the hepatic extracellular matrix involving matrix metalloproteinases (MMPs) occurs shortly after partial hepatectomy [57]. Hepatic stellate cells (HSCs) are the central effector of fibrosis in liver injury. Normally HSCs are quiescent, but in liver injury, undergo a myofibroblastic differentiation or activation, leading

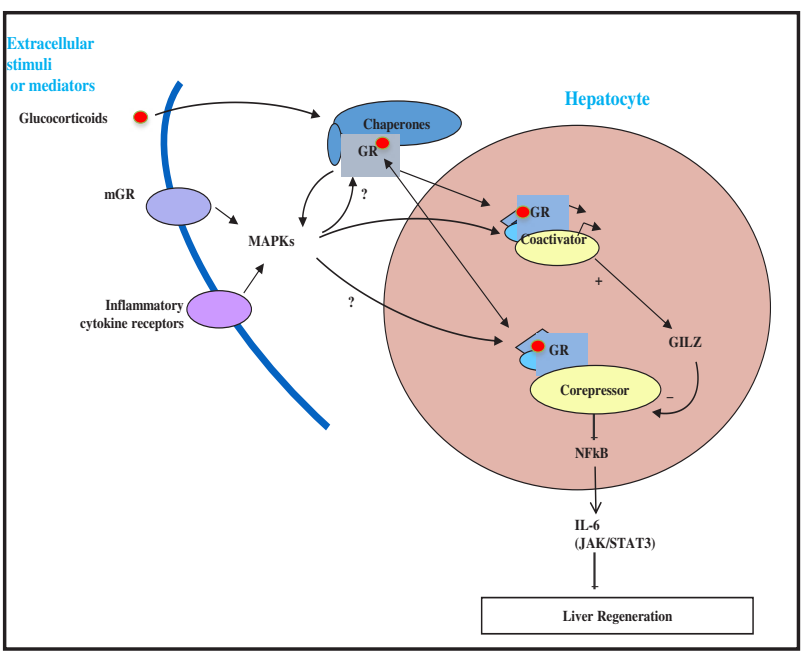

Fig. 1. Glucocorticoids cross talk with inflammatory cytokines affecting liver regeneration. Glucocorticoids (GCs) released from the hypothalamus-pituitary-adrenal (HPA) axis in response to psychosocial stress can either bind to major (membrane bound GR) or cytosolic GR to trigger immediate non-genomic pathways through activation of mitogenactivated protein kinases (MAPK). Nuclear translocation of GR is followed by GR interaction with transcriptional coregulators at distinct target gene promoters. GR interaction with transcriptional coactivators increases the expression of GILZ. Interaction of GR with transcriptional corepressors inhibits the expression of NFKB and subsequently IL-6 which influence liver regeneration through JAK/STAT3 pathway. to accumulation of extracellular matrix. As the liver injury resolves, the number of activated stellate cells decreases either by spontaneous reversion or clearance by apoptosis [58].

The TNF $\alpha$-IL6 signaling for liver regeneration appears to be a crucial pathway in early stages of liver injury [59-61]. Following cytokine activation, many other transcriptional factors and signal transduction pathways are activated $[6,61]$. Recently, it has been reported that Nrf2 pathway has been shown to regulate the cellular antioxidant response and improve the process of liver regeneration. It was shown that Nrf2/antioxidant response element (ARE) system is an effective way to control ALR expression necessary for hepatic regeneration [20]. Another study showed that ROS-induced Nrf2 is capable of triggering transcription of proteins that play vital role in cell redox homeostasis function [52]. Taken together, these studies provide evidence that the stress factors or mediators play an important role in the regulation of liver regeneration pathways.

\section{Stress-induced GCs affect TNF $\alpha$-IL6 signaling during liver regeneration}

Liver macrophages are key components involved in homeostasis and regression of hepatic disorder [62]. A pro-inflammatory cytokine $\mathrm{TNF} \alpha$ (released from macrophages) signaling is a prominent pathway in course of NFKB-prompted a liver cell proliferation. It has been shown that the NFKB signaling pathway regulate the proliferation of hepatic oval cells during liver regeneration. TNF $\alpha$ induces up-regulation of $\mathrm{NFKB}$ [51] which activates transcription of IL6 [6]. The IL6 is a critical mediator in liver, acute phase response and compensatory liver regeneration. In addition, animal model studies have proven the significance of IL6 in stimulating normal cell cycle progression and liver regeneration after partial hepatectomy 
$[1,63]$. Psychosocial stress-released GCs interaction with GR in Kupffer cells to increase GILZ expression and inhibit NFkB [50]. The GCs also inhibit IL6 via suppressing NFKB activation (Fig. 1).

\section{Stress-induced GCs affect nuclear factor Nrf2 during liver regeneration}

The keap1-Nrf2 pathway is a key regulator of cytoprotective responses to endogenous and exogenous stresses caused by ROS. Keap1, a cysteine rich cytoplasmic protein of hepatic cells, helps the quiescent Nrf2 complex formation in the cytoplasm and promotes its degradation by the ubiquitin proteasome pathway. Various stimuli trigger the detachment of this complex to initiate hepatic regeneration and oxidative stress. Liver pathologies produce greater extent of such oxidative stress. Most importantly, the stress-prompted GCs are well recognized to produce ROS [15]. Chronically released GCs increase ROS production in liver cells that causes the keap1-Nrf2 complexity of conformational changes resulting in detachment of Nrf2 from the quiescent complex and the release of the activated Nrf2 [24] which plays a role in liver regeneration. It has been reported that the absence of Nrf2 results in delayed liver regeneration after partial hepatectomy [54]. The Nrf2 regulates the expression of ALR which acts as antioxidative protein and plays an important role in liver regeneration to ensure the survival of the damaged cells [20]. Free Nrf2 translocate to the hepatic cell nucleus where it regulates the expression of several genes involved in cell proliferation (Fig. 2).

\section{Conclusion}

This review addresses the multi dimensional relationship of psychosocial stress involving Neuro-endocrine system, which affects liver regenerative pathways, food intake regulation and susceptibility to obesity. The schematic illustration is presented in Fig. 3. Distinct populations of neurons in the arcuate nucleus of hypothalamus contain appetite stimulators NPY and AgRP that are highly influenced by long-term stress resulting in altered physiological parameters and excessive

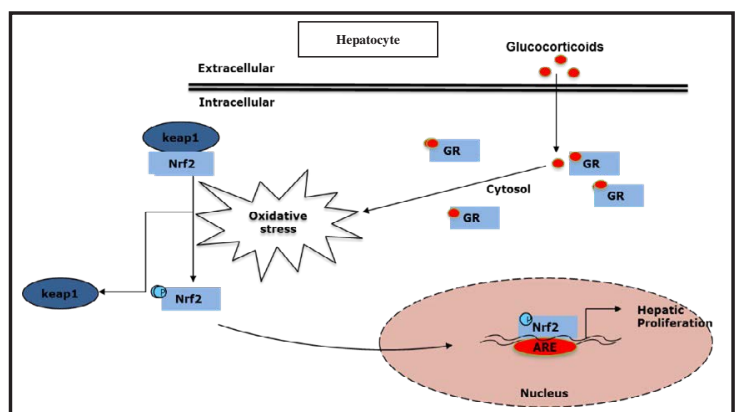

Fig. 2. GCs-induced oxidative stress regulates hepatic cell proliferation through the keap1-Nrf2 pathway. Increased GCs level causes oxidative stress due to excessive production of reactive oxygen species, which dissociate keap1-Nrf2 complex, resulting in nuclear localization of Nrf2 where it enhances the transcription of genes implicated in hepatocyte proliferation.

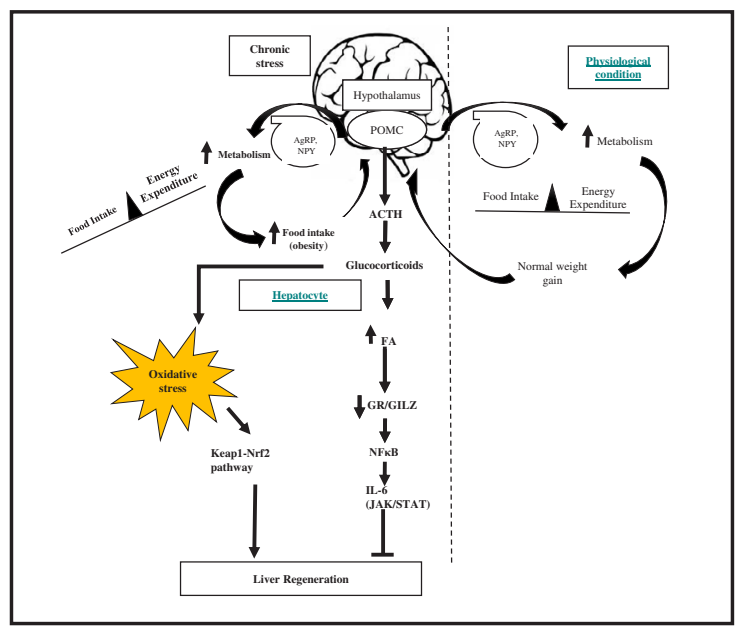

Fig. 3. Schematic illustration of the mechanism of stress-induced GCs-dependent weight gain, oxidative stress and liver generation. Under normal conditions, POMC cells, through the regulation of appetite stimulators AgRP and NPY, maintain balance between food intake and energy expenditure. In chronic stress, an increased weight gain occurs due to excessive activity of appetite stimulators and results in an imbalanced food intake and energy expenditure. Increased adrenocorticotropic hormone (ACTH) and glucocorticoids levels accompanied with obesitylinked high levels of fatty acids (FA) down regulates GILZ expression which increases NFKB and IL6 expression regulating the liver regeneration processes through JAK/STAT3 pathway. 


\section{Cellular Physiology Cell Physiol Biochem 2018;46:1-8

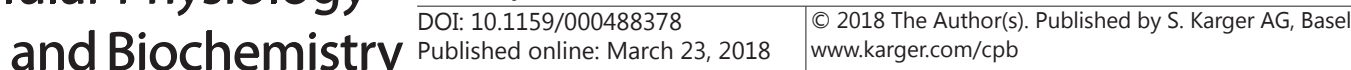

Ishtiaq et al.: Pathophysiological Impact of Stress on Liver Regeneration

weight gain leading to obesity. Noticeable rise in ROS production, as a result of excessive glucocorticoids secretion during prolonged stress, activates liver degenerative processes through extrinsic and intrinsic pathways of cell death. Alongside these detrimental effects of glucocorticoids, Keap1-Nrf2 pathway, which promotes liver regeneration, is also activated by the glucocorticoids. Thus, both apoptosis and regenerative pathways are fine-tuned by the glucocorticoids signaling and the outcome would be determined by alteration in any of the two mechanisms.

\section{Acknowledgements}

This work was supported by Higher Education Commission (HEC) Islamabad, Pakistan project number 6380/Punjab/NRPU/R\&D/HEC/2016.

\section{Disclosure Statement}

No conflict of interests exists.

\section{References}

1 Liu Y, Shao M, Wu Y, Yan C, Jiang S, Liu J, Dai J, Yang L, Li J, Jia W, Rui L: Role for the endoplasmic reticulum stress sensor IRE1 $\alpha$ in liver regenerative responses. J Hepatol 2015;62:590-598.

Michalopoulos GK: Liver regeneration. J Cell Physiol 2007;213:286-300.

Chen K, Li J, Li S, Feng J, Wu L, Liu T, Zhang R, Xu S, Cheng K, Zhou Y, Zhou S: 15d-PGJ2 alleviates ConAinduced acute liver injury in mice by up-regulating HO-1 and reducing hepatic cell autophagy. Biomed Pharmacother 2016;80:183-192.

4 Fausto N, Campbell JS: The role of hepatocytes and oval cells in liver regeneration and repopulation. Mech Dev 2003;120:117-130.

5 Fausto N: Liver regeneration and repair: Hepatocytes, progenitor cells, and stem cells. Hepatology 2004;39:1477-1487.

Taub R: Liver regeneration: from myth to mechanism. Nat Rev Mol Cell Biol 2004;5:836-847. Avgustinovich DF, Marenina MK, Zhanaeva SY, Tenditnik MV, Katokhin AV, Pavlov KS, Sivkov AY, Vishnivetskaya GB, Lvova MN, Tolstikova TG, Mordvinov VA: Combined effects of social stress and liver fluke infection in a mouse model. Brain Behav Immun 2016;53:262-272. Chida Y, Sudo N, Kubo C: Does stress exacerbate liver diseases? J Gastroenterol Hepatol 2006;21:202-208. Marsland AL, Walsh C, Lockwood K, John-Henderson NA: The effects of acute psychological stress on circulating and stimulated inflammatory markers: A systematic review and meta-analysis. Brain Behav Immun 2017;64:208-219.

10 Aschbacher K, O’Donovan A, Wolkowitz OM, Dhabhar FS, Su Y, Epel E: Good stress, bad stress and oxidative stress: Insights from anticipatory cortisol reactivity. Psychoneuroendocrinology 2013;38:1698-1708. Vere C-C: Psychosocial stress and liver disease status. World J Gastroenterol 2009;15:2980.

12 Gassen NC, Chrousos GP, Binder EB, Zannas AS: Life stress, glucocorticoid signaling, and the aging epigenome: Implications for aging-related diseases. Neurosci Biobehav Rev 2017;74:356-365.

13 Nguyen ET, Streicher J, Berman S, Caldwell JL, Ghisays V, Estrada CM, Wulsin AC, Solomon MB: A mixed glucocorticoid/mineralocorticoid receptor modulator dampens endocrine and hippocampal stress responsivity in male rats. Physiol Behav 2017;178:82-92.

14 Hewagalamulage SD, Lee TK, Clarke IJ, Henry BA: Stress, cortisol, and obesity: a role for cortisol responsiveness in identifying individuals prone to obesity. Domest Anim Endocrinol 2016;56:S112-S120.

15 Kansanen E, Kuosmanen SM, Leinonen H, Levonen A-L: The Keap1-Nrf2 pathway: Mechanisms of activation and dysregulation in cancer. Redox Biol 2013;1:45-49.

16 Duncan AW, Dorrell C, Grompe M: Stem Cells and Liver Regeneration. Gastroenterology 2009;137:466-481.

$>17$ Spector MS, Auer KL, Jarvis WD, Ishac EJ, Gao B, Kunos G, Dent P: Differential regulation of the mitogenactivated protein and stress-activated protein kinase cascades by adrenergic agonists in quiescent and regenerating adult rat hepatocytes. Mol Cell Biol 1997;17:3556-3565.

-18 Gandhi CR: Augmenter of liver regeneration. Fibrogenesis Tissue Repair 2012;5:10. 


\section{Cellular Physiology Cell Physiol Biochem 2018;46:1-8 \begin{tabular}{l|l} 
and Biochemistry Published online: March 23, 2018 & $\begin{array}{l}\text { (c) } 2018 \text { The Author(s). Published by S. Karger AG, Basel } \\
\text { www.karger.com/cpb }\end{array}$
\end{tabular}}

Ishtiaq et al.: Pathophysiological Impact of Stress on Liver Regeneration

19 Mu M, Zhang Z, Cheng Y, Liu G, Chen X, Wu X, Zhuang C, Liu B, Kong X, You S: Augmenter of liver regeneration (ALR) restrains concanavalin A-induced hepatitis in mice. Int Immunopharmacol 2016;35:280-286.

20 Dayoub R, Vogel A, Schuett J, Lupke M, Spieker SM, Kettern N, Hildt E, Melter M, Weiss TS: Nrf2 activates augmenter of liver regeneration (ALR) via antioxidant response element and links oxidative stress to liver regeneration. Mol Med 2013;19:237-244.

-21 Niiya T, Murakami M, Aoki T, Murai N, Shimizu Y, Kusano M: Immediate increase of portal pressure, reflecting sinusoidal shear stress, induced liver regeneration after partial hepatectomy. J Hepato-BiliaryPancreat Sci 1999;6:275-280.

22 Su AI, Guidotti LG, Pezacki JP, Chisari FV, Schultz PG: Gene expression during the priming phase of liver regeneration after partial hepatectomy in mice. Proc Natl Acad Sci 2002;99:11181-11186.

23 Fausto N: Liver regeneration. J Hepatol 2000;32:19-31.

-24 Suwanjang W, Abramov AY, Charngkaew K, Govitrapong P, Chetsawang B: Melatonin prevents cytosolic calcium overload, mitochondrial damage and cell death due to toxically high doses of dexamethasoneinduced oxidative stress in human neuroblastoma SH-SY5Y cells. Neurochem Int 2016;97:34-41.

25 Stanić D, Plećaš-Solarović B, Petrović J, Bogavac-Stanojević N, Sopić M, Kotur-Stevuljević J, Ignjatović S, Pešić V: Hydrogen peroxide-induced oxidative damage in peripheral blood lymphocytes from rats chronically treated with corticosterone: The protective effect of oxytocin treatment. Chem Biol Interact 2016;256:134-141.

26 Cohen S, Janicki-Deverts D, Miller GE: Psychological stress and disease. Jama 2007;298:1685-1687.

27 Jeong JH, Lee DK, Jo Y-H: Cholinergic neurons in the dorsomedial hypothalamus regulate food intake. Mol Metab 2017;6:306-312.

28 Yu C-H, Chu S-C, Chen P-N, Hsieh Y-S, Kuo D-Y: Participation of ghrelin signalling in the reciprocal regulation of hypothalamic NPY/POMC-mediated appetite control in amphetamine-treated rats. Appetite 2017;113:30-40.

-29 Alcántara-Alonso V, Amaya MI, Matamoros-Trejo G, de Gortari P: Altered functionality of the corticotrophinreleasing hormone receptor-2 in the hypothalamic paraventricular nucleus of hyperphagic maternally separated rats. Neuropeptides 2017;63:75-82.

-30 Harris RBS: Repeated restraint stress lowers the threshold for response to third ventricle CRF administration. Horm Behav 2017;89:64-68.

-31 Laraia BA, Leak TM, Tester JM, Leung CW: Biobehavioral Factors That Shape Nutrition in Low-Income Populations: A Narrative Review. Am J Prev Med 2017;52:S118-S126.

-32 Maida A, Zota A, Sjøberg KA, Schumacher J, Sijmonsma TP, Pfenninger A, Christensen MM, Gantert T, Fuhrmeister J, Rothermel U, Schmoll D: A liver stress-endocrine nexus promotes metabolic integrity during dietary protein dilution. J Clin Invest 2016;126:3263-3278.

-33 Mocanu V, Bontea A, Anton-Păduraru D: Eating Behavior in response to acute stress. Rev Med Chir Soc Med Nat Iasi 2016;120:223-227.

34 Peixoto-Silva N, Moura EG, Carvalho JC, Nobre JL, Quitete FT, Pinheiro CR, Santos-Silva AP, de Oliveira E, Lisboa PC: Bromocriptine treatment at the end of lactation prevents hyperphagia, higher visceral fat and liver triglycerides in early-weaned rats at adulthood. Clin Exp Pharmacol Physiol 2017;44:488-499.

35 Sinha R, Lacadie CM, Constable RT, Seo D: Dynamic neural activity during stress signals resilient coping. Proc Natl Acad Sci 2016;113:8837-8842.

-36 Moraitis AG, Block T, Nguyen D, Belanoff JK: The role of glucocorticoid receptors in metabolic syndrome and psychiatric illness. J Steroid Biochem Mol Biol 2017;165:114-120.

-37 Wagner M, Zollner G, Trauner M: Nuclear receptors in liver disease. Hepatology 2011;53:1023-1034.

-38 Rudraiah S, Zhang X, Wang L: Nuclear Receptors as Therapeutic Targets in Liver Disease: Are We There Yet? Annu Rev Pharmacol Toxicol 2016;56:605-626.

39 Liu H, Hai L, Tian J, Xiang J, Fan Y, Zhang H, Liu J, Zhang X: Anti-CD24 neutralizing antibody exacerbates Concanavalin A-induced acute liver injury in mice via liver M1 macrophages. Immunol Lett 2017;181:8793.

40 Nader N, Ng SSM, Lambrou GI, Pervanidou P, Wang Y, Chrousos GP, Kino T: AMPK Regulates Metabolic Actions of Glucocorticoids by Phosphorylating the Glucocorticoid Receptor through p38 MAPK. Mol Endocrinol 2010;24:1748-1764.

41 Novaes LS, dos Santos NB, Batalhote RFP, Malta MB, Camarini R, Scavone C, Munhoz CD: Environmental enrichment protects against stress-induced anxiety: Role of glucocorticoid receptor, ERK, and CREB signaling in the basolateral amygdala. Neuropharmacology 2017;113, Part A:457-466. 


\section{Cellular Physiology Cell Physiol Biochem 2018;46:1-8 \begin{tabular}{l|l} 
and Biochemistry Published online: March 23, 2018 & $\begin{array}{l}\text { D } 2018 \text { The Author(s). Published by S. Karger AG, Basel } \\
\text { www.karger.com/cpb }\end{array}$
\end{tabular}}

Ishtiaq et al.: Pathophysiological Impact of Stress on Liver Regeneration

42 Greulich F, Hemmer MC, Rollins DA, Rogatsky I, Uhlenhaut NH: There goes the neighborhood: Assembly of transcriptional complexes during the regulation of metabolism and inflammation by the glucocorticoid receptor. Steroids 2016;114:7-15.

43 Park EA, Gurney AL, Nizielski SE, Hakimi P, Cao Z, Moorman A, Hanson RW: Relative roles of CCAAT/ enhancer-binding protein beta and cAMP regulatory element-binding protein in controlling transcription of the gene for phosphoenolpyruvate carboxykinase (GTP). J Biol Chem 1993;268:613-619.

44 Hall RK, Sladek FM, Granner DK: The orphan receptors COUP-TF and HNF-4 serve as accessory factors required for induction of phosphoenolpyruvate carboxykinase gene transcription by glucocorticoids. Proc Natl Acad Sci 1995;92:412-416.

45 Jover R, Moya M, Gomez-Lechon MJ: Transcriptional Regulation of Cytochrome P450 Genes by the Nuclear Receptor Hepatocyte Nuclear Factor 4-Alpha. Curr Drug Metab 2009;10:508-519.

$\checkmark 46$ Wang JC, Strömstedt PE, O’Brien RM, Granner DK: Hepatic nuclear factor 3 is an accessory factor required for the stimulation of phosphoenolpyruvate carboxykinase gene transcription by glucocorticoids. Mol Endocrinol 1996;10:794-800.

47 Hall RK, Yamasaki T, Kucera T, Waltner-Law M, O’Brien R, Granner DK: Regulation of Phosphoenolpyruvate Carboxykinase and Insulin-like Growth Factor-binding Protein-1 Gene Expression by Insulin THE ROLE OF WINGED HELIX/FORKHEAD PROTEINS. J Biol Chem 2000;275:30169-30175.

48 Gulliver LSM: Xenobiotics and the Glucocorticoid Receptor. Toxicol Appl Pharmacol 2017;319:69-79.

-49 Ratman D, Vanden Berghe W, Dejager L, Libert C, Tavernier J, Beck IM, Tuckermann JP, Bouchet-Delbos L, Tran T, Hemon P, Puchois V: How glucocorticoid receptors modulate the activity of other transcription factors: A scope beyond tethering. Mol Cell Endocrinol 2013;380:41-54.

50 Robert O, Boujedidi H, Bigorgne A, Ferrere G, Voican CS, Vettorazzi S, Tuckermann JP, Bouchet-Delbos L, Tran T, Hemon P, Puchois V: Decreased expression of the glucocorticoid receptor-GILZ pathway in Kupffer cells promotes liver inflammation in obese mice. J Hepatol 2016;64:916-924.

-51 Zhao WM, Qin YL, Niu ZP, Chang CF, Yang J, Li MH, Zhou Y, Xu CS: Branches of the NF- $\kappa$ B signaling pathway regulate proliferation of oval cells in rat liver regeneration. Genet Mol Res 2016;15 DOI: 10.4238/ gmr.15017750

52 Wewering F, Jouy F, Caliskan S, Kalkhof S, von Bergen M, Luch A, Zellmer S: Hepatic co-cultures in vitro reveal suitable to detect Nrf2-mediated oxidative stress responses on the bladder carcinogen o -anisidine. Toxicol In vitro 2017;40:153-160.

53 de Sousa Rodrigues ME, Bekhbat M, Houser MC, Chang J, Walker DI, Jones DP, do Nascimento CMO, Barnum CJ, Tansey MG: Chronic psychological stress and high-fat high-fructose diet disrupt metabolic and inflammatory gene networks in the brain, liver, and gut and promote behavioral deficits in mice. Brain Behav Immun 2017;59:158-172.

54 Morales-González J, Madrigal-Santillán E, Morales-González Á, Bautista M, Gayosso-Islas E, SánchezMoreno C: What is Known Regarding the Participation of Factor Nrf-2 in Liver Regeneration? Cells 2015;4:169-177.

55 Tan CY, Lai RC, Wong W, Dan YY, Lim S-K, Ho HK: Mesenchymal stem cell-derived exosomes promote hepatic regeneration in drug-induced liver injury models. Stem Cell Res Ther 2014;5:76.

56 Bonecchi R, Garlanda C, Mantovani A, Riva F: Cytokine decoy and scavenger receptors as key regulators of immunity and inflammation. Cytokine 2016;87:37-45.

57 Böhm F, Köhler UA, Speicher T, Werner S: Regulation of liver regeneration by growth factors and cytokines. EMBO Mol Med 2010;2:294-305.

58 Canbay A, Friedman S, Gores GJ: Apoptosis: the nexus of liver injury and fibrosis. Hepatology 2004;39:273278.

59 Chen J, Chen L, Zern MA, Theise ND, Diehl AM, Liu P, Duan Y: The diversity and plasticity of adult hepatic progenitor cells and their niche. Liver Int 2017;37:1260-1271.

60 Mohammed FF, Pennington CJ, Kassiri Z, Rubin JS, Soloway PD, Ruther U, Edwards DR, Khokha R: Metalloproteinase inhibitor TIMP-1 affects hepatocyte cell cycle via HGF activation in murine liver regeneration. Hepatology 2005;41:857-867.

61 Murata S, Ohkohchi N, Matsuo R, Ikeda O, Myronovych A, Hoshi R: Platelets Promote Liver Regeneration in Early Period after Hepatectomy in Mice. World J Surg 2007;31:808-816.

62 Heymann F, Tacke F: Immunology in the liver — from homeostasis to disease. Nat Rev Gastroenterol Hepatol 2016;13:88-110.

-63 Iimuro Y, Nishiura T, Hellerbrand C, Behrns KE, Schoonhoven R, Grisham JW, Brenner DA: NFkappaB prevents apoptosis and liver dysfunction during liver regeneration. J Clin Invest 1998;101:802. 